\title{
Effects of Estrogen Replacement on Bone Geometry and Microarchitecture in Adolescent and Young Adult Oligoamenorrheic Athletes: A Randomized Trial
}

\author{
Kathryn E Ackerman ${ }^{1,2}$, Vibha Singhal ${ }^{1,3}$, Meghan Slattery ${ }^{1}$, Kamryn T Eddy $^{4}$, Mary L \\ Bouxsein $^{5}$, Hang Lee ${ }^{6}$, Anne Klibanski ${ }^{1}$, Madhusmita Misra ${ }^{1,3}$ \\ ${ }^{1}$ Neuroendocrine Unit, Massachusetts General Hospital and Harvard Medical School, Boston, \\ MA, USA \\ 2Division of Sports Medicine, Boston Children's Hospital and Harvard Medical School, Boston, \\ MA, USA \\ ${ }^{3}$ Division of Pediatric Endocrinology, Massachusetts General Hospital for Children and Harvard \\ Medical School, Boston, MA, USA \\ ${ }^{4}$ Eating Disorders Clinical and Research Program, Department of Psychiatry, Massachusetts \\ General Hospital and Harvard Medical School, Boston, MA, USA \\ ${ }^{5}$ Center for Advanced Orthopedic Studies, Beth Israel Deaconess Medical Center, Division of \\ Endocrinology, Massachusetts General Hospital, and Harvard Medical School, Boston, MA, USA \\ ${ }^{6}$ Biostatistics Center, Massachusetts General Hospital and Harvard Medical School, Boston, MA, \\ USA
}

\section{Abstract}

Oligoamenorrheic athletes (OAs) have lower bone mineral density (BMD) and greater impairment of bone microarchitecture, and therefore higher fracture rates compared to eumenorrheic athletes. Although improvements in areal BMD (aBMD; measured by dual-energy X-ray absorptiometry) in OAs have been demonstrated with transdermal estrogen treatment, effects of such treatment on bone microarchitecture are unknown. Here we explore effects of transdermal versus oral estrogen versus no estrogen on bone microarchitecture in OA. Seventy-five OAs (ages 14 to 25 years) were randomized to (i) a 100- $\mu$ g 17 $\beta$-estradiol transdermal patch (PATCH) administered continuously, with $200 \mathrm{mg}$ cyclic oral micronized progesterone given for 12 days of each month; (ii) a combined $30 \mu \mathrm{g}$ ethinyl estradiol and $0.15 \mathrm{mg}$ desogestrel pill (PILL); or (iii) no estrogen/progesterone (NONE) and were followed for 12 months. Calcium ( $\geq 1200 \mathrm{mg}$ ) and vitamin D (800 IU) supplements were provided to all. Bone microarchitecture was assessed using high-resolution

Address correspondence to: Kathryn E. Ackerman, MD, MPH, Sports Medicine, 319 Longwood Avenue, 6th Floor, Boston, MA 02115, USA. kathryn.ackerman@ childrens.harvard.edu.

Authors' roles: Study design: MM. Study conduct and data collection: MM, KEA, VS, MS, and KTE. Data analysis: MM and HL. Data interpretation: KEA, MM, and MLB. Drafting manuscript: KEA. Revising manuscript content: KEA and MM. Approving final version of manuscript: KEA, VS, MS, KTE, MLB, HL, AK, and MM. MM and HL take responsibility for the integrity of the data analysis.

Public clinical trial registration: http://clinicaltrials.gov/show/NCT00946192. Fat Mediated Modulation of Reproductive and Endocrine Function in Young Athletes. 
peripheral quantitative $\mathrm{CT}$ at the distal tibia and radius at baseline and 1 year. At baseline, randomization groups did not differ by age, body mass index, percent body fat, duration of amenorrhea, vitamin D levels, BMD, or bone microarchitecture measurements. After 1 year of treatment, at the distal tibia there were significantly greater increases in total and trabecular volumetric BMD (vBMD), cortical area and thickness, and trabecular number in the PATCH versus PILL groups. Trabecular area decreased significantly in the PATCH group versus the PILL and NONE groups. Less robust differences between groups were seen at the distal radius, where percent change in cortical area and thickness was significantly greater in the PATCH versus PILL and NONE groups, and changes in cortical vBMD were significantly greater in the PATCH versus PILL groups. In conclusion, in young OAs, bone structural parameters show greater improvement after 1 year of treatment with transdermal $17 \beta$-estradiol versus ethinyl estradiol-containing pills, particularly at the tibia.

\section{Keywords}

BONE QCT/ $\mu$ CT; DXA; ESTROGENS AND SERMs; FRACTURE PREVENTION; HORMONE REPLACEMENT/RECEPTOR MODULATORS

\section{Introduction}

The prevalence of amenorrhea in female athletes ranges from $3.4 \%$ to $66 \%$, varying by exercise type, intensity and duration, and nutritional status, ${ }^{(1-3)}$ compared with only $3 \%$ to $4 \%$ in the general population. ${ }^{(4)}$ Athletes who participate in endurance activities in which leanness is believed to confer a performance advantage are especially at risk for developing Female Athlete Triad (Triad), described as decreased energy availability (EA), menstrual dysfunction, and low bone mineral density (BMD). ${ }^{(5,6)}$ Low EA occurs when caloric intake does not keep pace with caloric expenditure, and may be inadvertent or purposeful. Such low EA, even while allowing for a normal body mass index (BMI), has negative effects on menstrual function and bone. ${ }^{(7-9)}$ In addition to the detrimental effects of hypogonadism to bone, ${ }^{(10,11)}$ low EA has negative effects on other hormones important for bone metabolism, such as insulin-like growth factor 1 (IGF-1) and leptin, ${ }^{(12,13)}$ even when weight is in the normal range.

Our studies and those of others have shown that the beneficial effects of weight-bearing exercise on bone during adolescence/young-adulthood are lost in oligoamenorrheic athletes (OAs), who have lower areal BMD (aBMD) and greater impairment of bone geometry and microarchitecture compared with eumenorrheic athletes, ${ }^{(11,14,15)}$ increasing their risk for fractures. ${ }^{(16)}$ Up to $24 \%$ of adolescent athletes experience oligoamenorrhea, ${ }^{(17)}$ with $78 \%$ of high school female athletes reporting at least one component of the Triad. ${ }^{(18)}$ Because adolescence is a critical time for bone acquisition, with $90 \%$ of peak bone mass typically achieved by 18 years, ${ }^{(19)}$ preventing and treating the Triad is critical for preventing future fractures.

Although combined oral contraceptive pills (COCs) are frequently prescribed to treat oligoamenorrhea and/or low BMD in adolescents and young women, there are little data to support this common practice. ${ }^{(20)}$ A systematic review of 75 studies of varying sample sizes 
and sample characteristics showed variably an increase, but more commonly a decrease or no change, in BMD with COCs. ${ }^{(21)}$ Ethinyl estradiol is the typical form of estrogen in COCs and is a nonphysiologic form of estrogen. Additionally, oral estrogen has hepatic first-pass effects, known to downregulate IGF-1, a hormone anabolic to bone. ${ }^{(22,23)}$ Thus, the type of estrogen and its oral delivery may explain its lack of efficacy in improving low BMD associated with low EA in individuals with oligoamenorrhea. ${ }^{(24)}$ We have shown that $17 \beta$ estradiol (17 $\beta$-E2) (the physiologic form of estrogen), administered via the transdermal route (avoiding hepatic effects), increases aBMD in low-weight girls with anorexia nervosa and normal-weight OA. ${ }^{(24,25)}$ However, effects on volumetric BMD (vBMD) and bone geometry and microarchitecture have not been reported.

Our objective was to determine the impact of a transdermal and physiologic form of estrogen replacement compared to a commonly used COC or no estrogen on changes in vBMD, bone geometry, and microarchitecture at the distal tibia and radius over 1 year in young normal-weight OAs engaged in weight-bearing activity of the lower extremities. We hypothesized that these bone parameters would improve over 12 months of transdermal 17 $\beta$ E2 administration compared to COCs or no estrogen treatment.

\section{Subjects and Methods}

\section{Subject selection}

The study was performed at the Massachusetts General Hospital Clinical Research Center. Participants were recruited through medical clinics, advertisements in local newspapers, and fliers at colleges and sporting events in the community. We screened 140 girls and young women 14 to 25 years for participation in our parent study, randomizing eligible OAs to transdermal estrogen with cyclic progesterone, $\mathrm{COC}$, or no treatment for 12 months, and assessed aBMD as the primary study outcome as reported. ${ }^{(24)}$ A total of 121 OAs met inclusion criteria and participated in the main study, ${ }^{(24)}$ of whom 75 had high-resolution peripheral quantitative computed tomography (HRpQCT) measurements performed at baseline and 12 months, and are reported here for the first time. Participants were required to have a bone age of $\geq 14$ years, because statural growth is mostly complete at this time, and estrogen administration in full replacement doses is unlikely to accelerate epiphyseal fusion and impact adult height. ${ }^{(26)}$ Subjects were also required to have a BMI that was $>10$ th percentile for age, $>85 \%$ of the median BMI (mBMI) for age, or $>17.5 \mathrm{~kg} / \mathrm{m}^{2}$ to avoid enrolling young women with active anorexia nervosa (per Diagnostic and Statistical Manual of Mental Disorders, 4th Edition [DSM-IV] ${ }^{(27)}$ criteria, because the 5th edition of the DSM $[D S M-5]^{(28)}$ criteria were not published at the time of enrollment). We used these parameters as a "low weight threshold."

Oligoamenorrhea was defined as the absence of menses for $\geq 3$ months within a period of oligomenorrhea (cycle length $>6$ weeks) for $\geq 6$ months, or absence of menarche at $\geq 15$ years, as ascertained by self-report. All subjects were screened by a study psychologist/ psychiatrist, and those meeting criteria for current active anorexia nervosa were excluded. Of note, all participants were above the "low weight threshold." 
Participants were all endurance athletes involved in $\geq 4$ hours of aerobic weight-bearing exercise of the legs (eg, basketball, soccer, dance) and/or $\geq 20$ miles of running weekly for $\succeq$ preceding months. Gymnasts, rowers, cyclists, and swimmers were excluded to minimize weight-bearing variability. Exclusion criteria also included conditions other than functional hypothalamic amenorrhea and endurance training that may cause oligoamenorrhea (eg, pregnancy, hyperprolactinemia, polycystic ovarian syndrome, premature ovarian failure, and thyroid dysfunction), use of medications affecting bone (eg, estrogen, progesterone, anabolic steroids, glucocorticoids, bisphosphonates, and teriparatide) in the 3 months preceding study enrollment, and other medical conditions that may affect bone. We did not exclude potential participants if they were taking calcium or vitamin D supplements. For subjects randomized to estrogen and progesterone treatment, exclusion criteria included complex migraines, a first-degree relative with estrogen-dependent cancer (eg, breast cancer), and a family or personal history of conditions that may increase the risk of thromboembolism.

The study was approved by the Institutional Review Board of Partners Healthcare. Informed consent was obtained from participants $\geq 18$ years old and parents of participants $<18$ years old. Informed assent was obtained from participants $<18$ years old.

\section{Experimental protocol}

Screening visit-At the screening visit, individuals underwent a complete history and physical examination. Height was measured on a wall-mounted stadiometer to the nearest millimeter (average of three measurements), and weight was measured on an electronic scale to the nearest $0.1 \mathrm{~kg}$. BMI was calculated as weight (in kilograms) divided by height (in meters) squared. Height and BMI $Z$-scores were obtained using Centers for Disease Control and Prevention (CDC) tables. ${ }^{(29)}$ A detailed exercise history was obtained to confirm that participants met endurance criteria. Average hours per week of different types of weightbearing activity over the preceding 6 months were calculated. A blood draw was performed to rule out other causes of oligoamenorrhea. A urine pregnancy test was performed. Subjects younger than 21 years old had a wrist and hand radiograph to determine bone age, assessed by both a radiologist and clinical endocrinologist to confirm that the bone age was $\geq 14$ years.

Baseline visit-The baseline visit, which occurred within 8 weeks of the screening visit, included an interval history and physical examination with anthropometric measurements; fasting levels of 25(OH) vitamin D, estradiol, sex hormone binding globulin (SHBG), and IGF-1; HRpQCT scans at the distal tibia and radius to assess vBMD, bone geometry, and bone microarchitecture; and assessment of resting energy expenditure (REE) using indirect calorimetry (VMAX Encore 29 metabolic cart; Viasys Healthcare, Carefusion, San Diego, CA, USA). ${ }^{(30)}$ Data for dual-energy X-ray absorptiometry (DXA) measures of BMD, lean mass, and fat mass and biochemical parameters have been reported in detail. ${ }^{(24,31)}$

OAs were randomized to physiological estrogen replacement via the transdermal 17- $\beta$ E2 patch (PATCH), estrogen replacement via a COC (PILL), or to the no estrogen (NONE) arm by our institution's research pharmacy based on a predetermined computer-generated randomization sequence. The PATCH group received the $100-\mu \mathrm{g}$ transdermal $17-\beta$ E2 patch 
applied twice weekly continuously and cyclic oral micronized progesterone $(200 \mathrm{mg})$ for 12 days of each month. Subjects were counseled that PATCH is not an effective form or dose of contraception and were reminded to use other nonhormonal forms of contraception as needed. The PILL group received a COC containing $30 \mu \mathrm{g}$ ethinyl estradiol with $0.15 \mathrm{mg}$ desogestrel. Doses of transdermal or oral estrogen were based on recommended replacement doses in this age group for hypogonadal individuals. ${ }^{(32)}$ The NONE group received no estrogen or progesterone. All subjects were given calcium and vitamin D supplementation and instructed to take at least $1200 \mathrm{mg}$ elemental calcium in divided doses and $800 \mathrm{IU}$ vitamin D daily. This study was not blinded given concerns that girls and women randomized to PATCH or NONE groups may assume they were on an oral contraceptive pill, and may not use appropriate contraception when necessary.

Follow-up visits-Follow-up visits included an interval history and physical examination, pregnancy test, and fasting blood draw every 3 months for the 12-month duration of the study to review adverse events and rule out pregnancy. Menstruating subjects in the NONE group were scheduled within 10 days of their menses to ensure blood specimens were drawn within the follicular phase. At each visit, participants were asked about any changes in their exercise habits. At these visits, we assessed compliance with study medications with verbal questionnaires and by collecting calendars provided to subjects for recording missed medication doses. We also collected used and unused patches and pills. Estradiol levels were assessed to confirm compliance in the transdermal PATCH group and SHBG levels were assessed as an objective measure of compliance in the PILL group, because levels of SHBG increase with oral ethinyl estradiol and desogestrel administration. ${ }^{(33,34)}$ Repeat HRpQCT scanning was performed at 12 months.

HRpQCT

vBMD, bone geometry, and microarchitecture were measured at the distal tibia and radius using HRpQCT (XtremeCT; Scanco Medical AG, Brüttisellen, Switzerland), as described. (11) Scans were acquired at the nondominant leg and wrist, unless there was a prior fracture in that limb, in which case the contralateral limb was used. Manufacturer's protocols were followed, including acquisition of a 2D scout view followed by CT slices obtained 22.5 and $9.5 \mathrm{~mm}$ from a reference line manually placed at the endplate of the tibia and radius, respectively. ${ }^{(35)}$ We chose fixed sites because most of their linear growth was complete in our participants. Scans used $60 \mathrm{kVp}$ effective energy and $100 \mathrm{~ms}$ integration time, obtaining $110 \mathrm{CT}$ slices $(9.02 \mathrm{~mm})$ with an isotropic voxel size of $82 \mu \mathrm{m}^{3}$. At our institution, root mean squares of coefficients of variation (RMS-CV) are $0.2 \%$ to $0.8 \%$ for density parameters (eg, total, trabecular, and cortical density), 3\% to $7 \%$ for trabecular microarchitecture, and 3\% to $8 \%$ for cortical microstructure. 2D image registration based on the total cross-sectional area was performed to align the baseline and follow-up scans, and the degree of overlap was $78 \%$ or higher for all subjects.

Outcomes at both the tibia and radius included total vBMD, cortical vBMD, cortical perimeter, cortical area, cortical thickness, trabecular vBMD, trabecular area, trabecular number, trabecular separation, and trabecular thickness. Effective total radiation dose from 
HRpQCT at the tibia and radius at baseline and 12 months was $20 \mu \mathrm{Sv}$ per participant. One participant each in the PILL and NONE groups did not have data for the tibia.

\section{Biochemical analysis}

25(OH) vitamin D was measured using an immunochemiluminometric assay (LabCorp

Esoteric Testing, Burlington, NC, USA; sensitivity $4.0 \mathrm{ng} / \mathrm{mL}$; intraassay CV $4.8 \%$ to $7.7 \%$ ). An electrochemiluminescence immunoassay was used to measure $17 \beta$ E2 (LabCorp Esoteric Testing; sensitivity $25.0 \mathrm{pg} / \mathrm{mL}$; intraassay CV 1.2\% to 6.7\%), and SHBG (LabCorp Esoteric Testing; $2.00 \mathrm{nmol} / \mathrm{L}$; intraassay CV $1.1 \%$ to $1.7 \%$ ), IGF-1 was measured using mass spectrometry (Quest Diagnostics, Nichols Institute, San Juan Capistrano, CA, USA; sensitivity $15.6 \mathrm{ng} / \mathrm{mL}$; intraassay CV $3.5 \%$ to $15 \%$ ); age-adjusted IGF- $Z$-scores were provided by Quest Diagnostics.

\section{Statistical methods}

We used SAS and JMP Statistical version 13.0 (SAS Institute, Inc., Cary, NC, USA) for all analyses and report data as means \pm SE. For baseline characteristics, our data were mostly normally distributed (except for estradiol levels) and did not require transformations. For comparison of baseline characteristics (except estradiol) among the three randomization groups, and changes in biochemical variables over time, we performed an overall ANOVA, followed by a Tukey-Kramer analysis to assess between-group differences while controlling for multiple comparisons. For comparison of estradiol levels, which were not normally distributed, the Kruskal-Wallis test was used. A two-tailed $p<0.05$ was considered significant. For the randomized controlled trial, we compared changes in HRpQCT measures among PATCH, PILL, and NONE groups over 12 months by performing multivariable regression analysis followed by the Dunnett's test to assess differences between PATCH versus PILL and PATCH versus NONE, while controlling for age, height, race, and ethnicity (consistent with the planned approach at study outset). Race and ethnicity were based on self-report. These data are reported as least square means \pm SE. Further, given differences among groups for menarcheal age and certain HRpQCT endpoints at baseline, we performed additional analyses also controlling for menarcheal age and for baseline measures. Our power calculation was based on preliminary data indicating that the estimated SD for percent change in aBMD over a year is $2.1 \%$ in those receiving transdermal estrogen versus no therapy. Specifically, using Dunnett's test, with a total of at least 72 OA (24 each in the two treatment arms and in the no-treatment arm), the study would have $80 \%$ power (using a two-sided alpha level of 0.05 ) to detect a difference of at least $1.7 \%$ in mean percent change in key HRpQCT parameters, such as $\mathrm{vBMD}$, in groups receiving transdermal versus oral estrogen or no estrogen (assuming that the oral estrogen arm would perform no better than no therapy). To determine associations between changes in hormone levels over the study duration in relation to changes in HRpQCT parameters over the same duration, Pearson correlations were performed. 


\section{Results}

\section{Baseline characteristics}

Baseline characteristics of participants randomized to PATCH, PILL, or NONE groups are shown in Table 1. The subset of participants who completed HRpQCT assessment at baseline and 12 months and are reported here did not differ from the larger group in the published parent study ${ }^{(24)}$ for clinical characteristics, and only relevant data are presented in this work (Fig. 1). Randomization groups did not differ for age, BMI, percent body fat, months since last menses, biochemical parameters, or resting energy expenditure. Type of menstrual dysfunction (amenorrhea, oligomenorrhea, irregularity) did not differ among groups (Table 1). Baseline aBMD measures have been reported, ${ }^{(24)}$ and did not differ among groups in this subset (data not shown). HRpQCT measurements did not differ among groups at baseline, except for slightly lower cortical vBMD and thickness at the distal radius in the PATCH versus PILL groups ( $p=0.034$ and $p=0.033$, respectively). Due to previous fractures, 12 contralateral radii were scanned (PATCH: 6, PILL: 4, NONE: 2) and 11 contralateral tibias (PATCH: 3, PILL: 2, NONE: 6); these were not different across groups (data not shown). Changes in height, weight, BMI, fat mass, and lean mass did not differ among PATCH, PILL, and NONE groups.

\section{Changes in aBMD over 12 months}

Change and percent change in lumbar spine, femoral neck, and total hip BMD in this subset reflected reported changes at these sites in the parent study ${ }^{(24)}$ and are not reported again.

\section{Changes in HR-pQCT parameters over 12 months}

Weight-bearing distal tibia-Table 2 shows changes at 12 months in HRpQCT results at the distal tibia after controlling for age, height, race, and ethnicity. The PATCH versus PILL group demonstrated greater percent increases in total vBMD $(2.4 \% \pm 1.0 \%$ versus $0.5 \% \pm$ $1.0 \%, p=0.010)$, trabecular vBMD $(1.6 \% \pm 1.1 \%$ versus $0.1 \% \pm 1.1 \%, p=0.069[p=0.037$ for absolute change]), cortical area $(3.1 \% \pm 1.8 \%$ versus $-0.3 \% \pm 1.8 \%, p=0.007)$, cortical thickness $(0.03 \% \pm 0.02 \%$ versus $-0.00 \% \pm 0.02 \%, p=0.020)$, and trabecular number $(5.1 \%$ $\pm 4.3 \%$ versus $-0.7 \% 4.3 \%, p=0.076$ [ $p=0.043$ for absolute change]) (Fig. 2A,B). Further, PATCH had greater percent reductions than PILL in trabecular area $(-0.5 \% \pm 0.3 \%$ versus $-0.10 \% \pm 0.3 \%, p=0.040)$ and separation $(-5.4 \% \pm 4.3 \%$ versus $1.2 \% \pm 4.3 \%, p=0.040)$. PATCH versus NONE had greater percent increase in cortical area $(3.1 \% \pm 1.8 \%$ versus $0.5 \% \pm 1.9 \%, p=0.044)$ and decrease in trabecular area $(-0.5 \% \pm 0.3 \%$ versus $-0.2 \% \pm$ $0.3 \%, p=0.076[p=0.036$ for absolute change $]$ ) (Fig. 2B).

After also controlling for baseline measures (in addition to age, height, race, and ethnicity), differences between PATCH and PILL groups persisted for changes in total vBMD ( $p=$ $0.02)$, cortical area $(p=0.01)$, trabecular area $(p=0.02)$, and cortical thickness $(p=0.04)$, but differences were attenuated to a trend level for trabecular vBMD and trabecular number $(p<0.10)$. Differences between PATCH and NONE groups persisted for change in trabecular area $(p=0.03)$. 
Similarly, when we added menarcheal age to the multivariable regression model, differences between PATCH and PILL groups for total vBMD $(p=0.04)$, cortical and trabecular area $(p$ $=0.02$ and $p=0.04)$, and cortical thickness $(p=0.048)$ persisted, as did the differences for percent change in total vBMD, cortical area, and thickness. However, differences between groups for trabecular vBMD and number were lost after controlling for menarcheal age.

Non-weight-bearing radius-Table 3 illustrates the changes over 12 months in HRpQCT parameters at the distal radius. After controlling for age, height, race, and ethnicity, percent changes in cortical vBMD $(4.6 \% \pm 1.5 \%$ versus $2.4 \% \pm 1.5 \%, p=0.047)$, area $(22.2 \% \pm 12.4 \%$ versus $2.4 \% \pm 12.4 \%, p=0.030)$, and thickness $(20.9 \% \pm 9.4 \%$ versus $5.6 \% \pm 9.4 \%, p=0.025$ ) were greater in the PATCH versus PILL groups (Fig. 2). Percent changes in cortical area $(22.2 \% \pm 12.4 \%$ versus $3.3 \% \pm 13.5 \%, p=0.032)$ and thickness $(20.9 \% \pm 9.4 \%$ versus $5.8 \% \pm 10.2 \%, p=0.022)$ were greater in the PATCH versus NONE groups (Fig. 2C,D). Baseline cortical vBMD and thickness at the radius differed among groups (Table 1). Controlling for baseline, cortical vBMD attenuated differences among groups for changes in cortical vBMD over time. However, increases in cortical thickness trended higher in the PATCH versus PILL group, even after controlling for baseline cortical thickness $(p=0.067)$. These differences were lost after controlling for menarcheal age.

\section{Changes in biochemical parameters over 12 months}

Changes in vitamin D, estradiol, and SHBG levels and IGF-1 Z-scores have been reported for the full cohort, ${ }^{(24,31)}$ and are reported here for the subset. Changes in $25(\mathrm{OH})$ vitamin $\mathrm{D}$ levels over 12 months in this subset did not differ among groups $(p=0.55)$. The PATCH group had greater increases in estradiol compared to the PILL and NONE groups (mean [IQR], $42.0[7.0,57.7)$ versus $-17.5[-81.8,0.0] \mathrm{pg} / \mathrm{mL}$ and $-5.0[-14.0,52.7] \mathrm{pg} / \mathrm{mL}, p<$ 0.05 for both), lesser increases in SHBG $(1.0 \pm 3.8$ versus $155.6 \pm 22.1 \mathrm{nmol} / \mathrm{L}, p<0.0001)$, and lesser reductions in IGF-1 $Z$-scores $(-0.02 \pm 0.17$ versus $-0.61 \pm 0.22, p=0.050)$ compared with the PILL group. The PILL group had greater increases in SHBG than both other groups, similar to the parent study $(p<0.0001) .{ }^{(24)}$ Together this suggests more bioavailable estradiol in the PATCH group compared to both PILL and NONE groups during the study, and overall, good compliance with study medications in the PATCH and PILL groups.

At 12 months, at the distal tibia, changes in estradiol levels were associated with changes in total vBMD $(r=0.35, p=0.005)$ (Fig. 3A), trabecular vBMD $(r=0.28, p=0.027)$ (Fig. 3B), cortical thickness $(r=0.41, p=0.0009)$ (Fig. 3C), cortical area $(r=0.43, p=0.0005)$ (Fig. 3D), trabecular area $(r=-0.43, p=0.0004)$ (Fig. 3E), trabecular number $(r=0.32, p=$ $0.009)$, and trabecular separation $(r=-0.28, p=0.024)$ (Fig. 3F).

\section{Adverse events}

Subjects were asked about adverse events throughout the study, during phone calls and at follow-up visits. There were no significant differences among the groups for adverse events, including no differences in headache, breast tenderness, bloating, skin rash, or fracture (Table 4). ${ }^{(24)}$ 


\section{Discussion}

This is the first study to demonstrate the efficacy of transdermal 17 $\beta$-E2 replacement in improving vBMD, bone geometry, and bone microarchitecture in $\mathrm{OA}$, a population at high risk for stress fractures from overuse and hormonal suppression, and long-term consequences of suboptimal peak bone mass acquisition. ${ }^{(6,16)}$ In fact, it is the first study to investigate the effects of estrogen administration in any form on HRpQCT measurements in a cohort of premenopausal women. Our previously published work demonstrated that OAs receiving transdermal estradiol with cyclic oral progesterone (PATCH) had an increase in lumbar spine, femoral neck, and total hip aBMD at 6 and 12 months (as measured by DXA) compared to those receiving ethinyl estradiol and a progestogen via a standard COC (PILL). (24) The PATCH group also had greater increases in lumbar spine and femoral neck BMD than the no-estrogen group at 12 months. ${ }^{(24)}$ Our current study builds on that work to show superior effects of transdermal 17 $\beta$-E2 replacement compared to COC on peripheral bone density and microarchitecture, particularly at the weight-bearing distal tibia.

Our study shows that at the weight-bearing tibia, the PATCH compared to the PILL group had greater increases in total and trabecular vBMD, cortical area and thickness, and trabecular number. The PATCH versus PILL group also had a greater percent decrease in trabecular separation, consistent with an increase in trabecular number. The PATCH group did have an increase in cortical area, but a decrease in trabecular area compared to the other two groups.

The decrease in trabecular area was expected given that estradiol reduces endosteal bone resorption. ${ }^{(36)}$ Animal and human studies support that cortical and trabecular bone are regulated differently by various cell types (eg, osteoblast progenitors and osteoclasts), resulting in contrasting responses to hormonal and mechanical signaling. ${ }^{(37)}$ Of note, we expected trabecular area to decrease more in the PILL group as well. The lack of this effect in the PILL group needs to be studied further, but may reflect significant increases in SHBG in the PILL group that were not seen in the other two groups, resulting in a reduction in the amount of bioavailable estrogen. ${ }^{(38)}$ In general, effects of estrogen appear to be attenuated in adolescents/young adults compared to older women based on prior studies. ${ }^{(39,40)}$ This may explain why we did not see more robust effects on trabecular vBMD and other trabecular components. We also found reductions in preadipocyte factor-1 and brain-derived neurorophic factor within the PATCH group that were not observed in the PILL group. ${ }^{(31)}$ It is unclear if these changes have differential effects on cortical versus trabecular bone.

We previously found that in contrast to the non-weight-bearing radius, the weight-bearing tibia was slightly more protected from bone deficits in amenorrheic exercisers. ${ }^{(11,14)}$ Of the improvements in tibial HRpQCT parameters observed in our current study, only total vBMD, trabecular number, and trabecular spacing differed cross-sectionally in amenorrheic versus eumenorrheic athletes and non-athletes. ${ }^{(11)}$ Improvements in multiple tibial parameters with physiologic estrogen replacement has implications for reduced fracture risk. $(14,16,41)$ 
At the non-weight-bearing radius, the PATCH group had greater gains over 12 months in cortical area and thickness compared to the other two groups. The more pronounced effects of PATCH at the tibia compared to the radius likely reflect the interaction between mechanical loading and estrogen on the skeleton, with estrogen having permissive effects on the skeletal impact of mechanical loading. ${ }^{(36)}$ In a previously reported cross-sectional study, radial cortical area and thickness were noted to be lower in amenorrheic athletes than eumenorrheic athletes and non-athletes. ${ }^{(11)}$ Our present study suggests that physiologic estrogen and progesterone replacement may improve such differences. These results differ somewhat from those reported by Farr and colleagues ${ }^{(42)}$ in a different population: recently postmenopausal women. Subjects received placebo, $0.45 \mathrm{mg} / \mathrm{d}$ equine estrogens orally, or 50 $\mu \mathrm{g} / \mathrm{d} 17 \beta-\mathrm{E} 2$ transdermally. Both estrogen groups received $200 \mathrm{mg}$ micronized progesterone for 12 days of each month. After 4 years, cortical vBMD decreased and porosity increased in women receiving placebo. Estradiol given orally or transdermally prevented these changes. However, there were no differences in changes in radial cortical area or thickness across groups. ${ }^{(42)}$ This is the only other study to date that has examined effects of hormonal treatment on HRpQCT measured parameters in an estrogen-deficient population, with obvious differences in study design (including type and dose of estrogen), study duration, and study population. Beyond this, we are only aware of 12 studies that have examined effects of any treatment on HRpQCT-measured bone outcomes in women. ${ }^{(43)}$

As we have previously reported for the effects of PATCH versus PILL or NONE on DXA measures, the fact that the PATCH is more beneficial for HRpQCT parameters can likely be explained by the fact that (i) transdermal $17 \beta$-E2 does not experience first-pass metabolism at the liver and thus does not suppress IGF-1 secretion, a bone-trophic hormone downregulated by COCs ${ }^{(44)}$ (as also noted in the current sample); (ii) higher SHBG levels in the PILL group ${ }^{(34,45)}$ may further reduce bioavailable estradiol, essential for bone accrual and maintenance ${ }^{(36)}$; and (iii) the formulation of COC used for this study (30 $\mu$ ethinyl estradiol, $0.15 \mathrm{mg}$ desogestrel) resulted in a decrease in serum estradiol versus the PATCH group, which had an increase in estradiol compared to baseline. The last likely reflects the estradiol assay, which measures $17 \beta$-E2, and not ethinyl estradiol, the estrogen formulation in the COC; however, 17 $\beta$-E2 may be more effective in optimizing bone outcomes. A study of premenopausal women who received a COC containing $17 \beta-\mathrm{E} 2$ and nomegestrol acetate versus a COC containing ethinyl estradiol/levonorgestrel attempted to address this. After 2 years, there were no differences between groups for bone outcomes. ${ }^{(46)}$ In our study, we found significant associations of changes in serum estradiol levels over time with changes in HRpQCT measures of vBMD, bone geometry, and structure.

Further studies are necessary to determine whether lower doses of ethinyl estradiol may cause lesser increases in SHBG, and therefore cause different impacts on bone. Cibula and colleagues $^{(47)}$ reported lower BMD with the $15-\mu \mathrm{g}$ vs. the 30- $\mu$ g ethinyl estradiol COC formulation in adolescent girls. Scholes and colleagues ${ }^{(48)}$ found a trend for lower BMD with longer duration of use and lower estradiol dose formulations in young women. However, others have not found BMD effects of different COC estradiol dosages. ${ }^{(49,50)}$ More work is needed comparing COCs with various estradiol formulations and doses, but similar progesterone/progestogens, to elucidate the impact of estradiol formulation and dose on bone. 
Of note, the PATCH group received 17 $\beta$-E2 continuously, while the COC group received pills in the standard recommended fashion with 21 days of active and 7 days of placebo pills. Overall greater estrogen exposure in the PATCH versus PILL groups may have impacted outcomes more favorably. However, worse outcomes for changes in cortical area at the tibia and radius in PILL versus PATCH and NONE groups suggest possibly detrimental effects of COCs on bone microarchitecture, which may have been worse with continuous use of active pills.

Although it is commonly discussed that estrogen acts on bone by inhibiting bone resorption, animal cell culture studies have demonstrated that $17 \beta$-E2 may enhance bone formation at physiologic doses, and potentially bone resorption at higher doses. ${ }^{(51,52)}$ However, thus far, ethinyl estradiol has been shown to inhibit osteoclastic bone resorption in some, but not all animal tissue and human studies, and has not demonstrated an effect on bone formation. (53-55) In two human studies, ethinyl estradiol (via COC and via transdermal patch) attenuated bone accrual in adolescents/young women. ${ }^{(56,57)}$ In our study, as we previously reported, over the 12 months, $\mathrm{N}$-terminal propeptide of type 1 procollagen, a marker of bone formation, decreased the most in the PILL group, but again, this was associated with a decrease in IGF-1 levels. ${ }^{(31)}$ Thus, not only route, but type of estrogen replacement may be important for metabolic bone effects.

Studies suggest a possible role of progesterone/progestins on bone metabolism. In a metaanalysis, Seifert-Klauss and Prior ${ }^{(58)}$ indicated that regular ovulation (associated with increases in progesterone) likely contributes to peak BMD. Additionally, oral cyclic medroxyprogesterone acetate (MPA) increases BMD in healthy, normal-weight, physically active premenopausal women with oligoamenorrhea or subclinical ovulatory disturbances. (58,59) However, in a small, 1-year study of oligoamenorrheic teenagers who were underweight and/or had anorexia nervosa, oral cyclic MPA did not prevent bone loss. ${ }^{(58,60)}$ Further, depot MPA leads to bone loss in adolescent and adult premenopausal women. ${ }^{(61-67)}$ No studies to date have examined effects of oral progesterone alone on BMD in young women. Thus, it is unclear whether 12 days of micronized progesterone each month in the PATCH group may have impacted bone differently versus 21 days of desogestrel every month in the COC group. It is also important to note that we used two different types of progesterone; micronized progesterone (PATCH) commonly prescribed for hormonal replacement therapy and desogestrel (PILL) a type of progesterone found in some COC pills. The PATCH micronized progesterone dose $(200 \mathrm{mg})$ was much higher than the PILL desogestrel dose $(0.15 \mathrm{mg})$, but the active form of desogestrel has a higher affinity for the progesterone receptor than micronized progesterone. ${ }^{(68,69)}$ It is unclear if type and potency of progesterone contributed to our findings.

Although it is important for patients with Triad to focus on increasing EA to improve hormonal function (which will result in improving bone health), many patients are resistant to such changes in lifestyle. Triad treatment typically involves a team of specialists (eg, physician, dietitian, psychologist) to aid in such behavioral changes. ${ }^{(6)} \mathrm{A}$ "normal weight" athlete may find it just as disturbing to gain weight as a traditionally lower-weight patient with anorexia nervosa due to body image issues, and societal and sport pressures. ${ }^{(70,71)}$ To decrease bone loss and perhaps enhance bone accrual, physiologic transdermal 17 $\beta$-E2 with 
cyclic progesterone may be an appropriate adjunct treatment for these young women. This is particularly important during the adolescent years of peak bone accrual. ${ }^{(72)}$

There are limitations to our study. Trends in differences in various HRpQCT parameters were noted, as expected, but often did not reach a significance of $p<0.05$. More participants in each treatment arm may have improved the significance of some findings as may a longer duration of study. Additionally, although BMD improvements with PATCH have been reported, ${ }^{(24)}$ the relatively new usage of HRpQCT in premenopausal women makes interpreting the bone microarchitecture changes in our current study slightly more difficult. However, based on existing literature, we suspect that it is an improvement to see increases in cortical area and thickness and decreases in trabecular area. ${ }^{(16,73)}$ Our data for strength estimates are pending micro-finite element analysis using registered images. In older adults, Samelson and colleagues ${ }^{(73)}$ demonstrated correlations between HRpQCT measurements and fracture risk, independent of DXA-measured BMD. Our group found correlations with history of stress fractures and BMD and bone microarchitecture in OAs. ${ }^{(16)}$ Further prospective studies are needed to determine if the changes in bone microarchitecture from PATCH correlate with decreased future fracture risk. Additionally, we utilized one dose of transdermal 17 $\beta$-E2 and one dose and type of COC. Estradiol levels measured during treatment in the PATCH group were in the range that one aims for with hormonal replacement therapy, ${ }^{(74)}$ but other doses may need to be considered. The ethinyl estradiol dose in the PILL was a standard dose that is reasonably representative of COC use in the general population, ${ }^{(75)}$ but again, different doses and formulations may yield slightly different results. Further studies are necessary to compare other transdermal $17 \beta-\mathrm{E} 2$ and COC formulations and determine the role of progesterone (if any) on bone endpoints. Another consideration is that although we required study participants to be off COCs or other hormonal contraception for at least 3 months before study entry, we do not have the history of lifelong exposure to these substances in our participants. However, given the randomized nature of treatment allocation, we do not expect this to differ among groups. Finally, we do not have data for fracture prevalence, and larger studies are necessary to address this limitation.

Strengths of this work include the following: (i) participants were all endurance, weightbearing OAs, who met specific activity type and volume criteria (to limit lifestyle confounding effects); (ii) we used a state-of-the art modality (HRpQCT) to assess small differences in bone to better understand treatment effects; and (iii) we monitored compliance and effects with questionnaires and laboratory testing.

In conclusion, this is the first study to examine effects of transdermal physiologic estrogen replacement with cyclic progesterone on HRpQCT measures in OA. We compared this treatment, not only to no treatment, but also to a typically prescribed COC. We found that transdermal $17 \beta$-E2 was superior to a typical COC in improving many bone outcomes and may be superior in some aspects compared to no therapy as well. These results, along with the improvements in $\mathrm{aBMD}^{(24)}$ and bone turnover markers ${ }^{(31)}$ we have reported in PATCH versus PILL and PATCH versus NONE, suggest an overall superiority of transdermal 17 $\beta$ E2 as an adjunct treatment to improve skeletal health in female athletes with oligoamenorrhea.

J Bone Miner Res. Author manuscript; available in PMC 2021 February 01. 


\section{Acknowledgments}

This work was supported by grants from the NIH (R0I HD060827, K24 HD071843, UL1TR001102, S10 RR023045, K23DK 110419, P30 DK 040561, and P30 DK 057521). We thank our study participants and clinical research staff for their help and cooperation with this study.

Disclosures

Dr. Misra is a co-investigator on an investigator-initiated grant from Novo Nordisk, and a consultant for Sanofi Pharmaceuticals. Dr. Klibanski is a Board member of Albireo Pharmaceuticals and on the Scientific Advisory Board of Crinetics Phamaceuticals. She is the primary investigator of an investigator-initiated grant from Ipsen. None of these conflicts are relevant to the current study. The remaining authors have no conflicts of interest.

\section{References}

1. Loucks AB, Horvath SM. Athletic amenorrhea: A review. Med Sci Sports Exerc. 1985;17(1):56-72. [PubMed: 3920472]

2. Otis CL. Exercise-associated amenorrhea. Clin Sports Med. 1992;11(2): 351-62. [PubMed: 1591791]

3. Shangold M, Rebar RW, Wentz AC, Schiff I. Evaluation and management of menstrual dysfunction in athletes. JAMA. 1990;263(12): 1665-9. [PubMed: 2407876]

4. Practice Committee of the American Society for Reproductive Medicine. Current evaluation of amenorrhea. Fertil Steril. 2004;82(Suppl 1):S33-9. [PubMed: 15363691]

5. Nattiv A, Loucks AB, Manore MM, et al. American College of Sports Medicine position stand. The female athlete triad. Med Sci Sports Exerc. 2007;39(10):1867-82. [PubMed: 17909417]

6. De Souza MJ, Nattiv A, Joy E, et al. 2014 Female Athlete Triad Coalition Consensus Statement on Treatment and Return to Play of the Female Athlete Triad: 1st International Conference held in San Fran-cisco, California, May 2012 and 2nd International Conference held in Indianapolis, Indiana, May 2013. Br J Sports Med. 2014;48(4):289. [PubMed: 24463911]

7. Loucks AB, Verdun M, Heath EM. Low energy availability, not stress of exercise, alters LH pulsatility in exercising women. J Appl Physiol. 1998;84(1):37-46. [PubMed: 9451615]

8. Southmayd EA, Mallinson RJ, Williams NI, Mallinson DJ, De Souza MJ. Unique effects of energy versus estrogen deficiency on multiple components of bone strength in exercising women. Osteoporos Int. 2017;28(4):1365-76. [PubMed: 28032184]

9. Ihle R, Loucks AB. Dose-response relationships between energy availability and bone turnover in young exercising women. J Bone Miner Res. 2004;19(8):1231-40. [PubMed: 15231009]

10. De Souza MJ, West SL, Jamal SA, Hawker GA, Gundberg CM, Williams NI. The presence of both an energy deficiency and estrogen deficiency exacerbate alterations of bone metabolism in exercising women. Bone. 2008;43(1):140-8. [PubMed: 18486582]

11. Ackerman KE, Nazem T, Chapko D, et al. Bone microarchitecture is impaired in adolescent amenorrheic athletes compared with eumenorrheic athletes and nonathletic controls. J Clin Endocrinol Metab. 2011;96(10):3123-33. [PubMed: 21816790]

12. Misra M, Klibanski A. Endocrine consequences of anorexia nervosa. Lancet Diabetes Endocrinol. 2014;2(7):581-92. [PubMed: 24731664]

13. Ackerman KE, Misra M. Bone health and the female athlete triad in adolescent athletes. Phys Sportsmed. 2011;39(1):131-41. [PubMed: 21378496]

14. Ackerman KE, Putman M, Guereca G, et al. Cortical microstructure and estimated bone strength in young amenorrheic athletes, eumenorrheic athletes and non-athletes. Bone. 2012;51(4):680-7. [PubMed: 22878154]

15. Rencken ML, Chesnut CH 3rd, Drinkwater BL. Bone density at multiple skeletal sites in amenorrheic athletes. JAMA. 1996;276(3):238-40. [PubMed: 8667570]

16. Ackerman KE, Cano Sokoloff N, De Nardo Maffazioli G, Clarke HM, Lee H, Misra M. Fractures in relation to menstrual status and bone parameters in young athletes. Med Sci Sports Exerc. 2015;47(8): 1577-86. [PubMed: 25397605] 
17. Nichols JF, Rauh MJ, Lawson MJ, Ji M, Barkai HS. Prevalence of the female athlete triad syndrome among high school athletes. Arch Pediatr Adolesc Med. 2006;160(2):137-42. [PubMed: 16461868]

18. Hoch AZ, Pajewski NM, Moraski L, et al. Prevalence of the female athlete triad in high school athletes and sedentary students. Clin J Sport Med. 2009;19(5):421-8. [PubMed: 19741317]

19. Bailey DA, McKay HA, Mirwald RL, Crocker PR, Faulkner RA. A six-year longitudinal study of the relationship of physical activity to bone mineral accrual in growing children: The university of Saskatchewan bone mineral accrual study. J Bone Miner Res. 1999;14(10):1672-9. [PubMed: 10491214]

20. Gordon CM, Ackerman KE, Berga SL, et al. Functional hypothalamic amenorrhea: an Endocrine Society clinical practice guideline. J Clin Endocrinol Metab. 2017;102(5):1413-39. [PubMed: 28368518]

21. Liu SL, Lebrun CM. Effect of oral contraceptives and hormone replacement therapy on bone mineral density in premenopausal and perimenopausal women: A systematic review. Br J Sports Med. 2006;40(1):11-24. [PubMed: 16371485]

22. O'Connell MB. Pharmacokinetic and pharmacologic variation between different estrogen products. J Clin Pharmacol. 1995;35(9 Suppl):18S-24S. [PubMed: 8530713]

23. Yakar S, Rosen CJ, Beamer WG, et al. Circulating levels of IGF-1 directly regulate bone growth and density. J Clin Invest. 2002;110 (6):771-81. [PubMed: 12235108]

24. Ackerman KE, Singhal V, Baskaran C, et al. Oestrogen replacement improves bone mineral density in oligo-amenorrhoeic athletes: a randomised clinical trial. Br J Sports Med. 2019;53(4):229-36. [PubMed: 30301734]

25. Misra M, Katzman D, Miller KK, et al. Physiologic estrogen replacement increases bone density in adolescent girls with anorexia nervosa. J Bone Miner Res. 2011;26(10):2430-8. [PubMed: 21698665]

26. Kuczmarski RJ, Ogden CL, Guo SS, et al. CDC growth charts for the United States: methods and development. Vital Health Stat. 2000; 11(246):1-190.

27. American Psychiatric Association. Task Force on DSM-IV. Diagnostic and Statistical Manual of Mental Disorders: DSM-IV, vol. xxvii 4th ed Washington, DC: American Psychiatric Association; 1994 p 886.

28. American Psychiatric Association. DSM-5 Task Force. Diagnostic and Statistical Manual of Mental Disorders : DSM-5, vol. xliv 5th ed Washington, D.C: American Psychiatric Association; 2013 p 947.

29. Ogden CL, Kuczmarski RJ, Flegal KM, et al. Centers for Disease Control and Prevention 2000 growth charts for the United States: improvements to the 1977 National Center for Health Statistics version. Pediatrics. 2002;109(1):45-60. [PubMed: 11773541]

30. Mifflin MD, St Jeor ST, Hill LA, Scott BJ, Daugherty SA, Koh YO. A new predictive equation for resting energy expenditure in healthy individuals. Am J Clin Nutr. 1990;51(2):241-7. [PubMed: 2305711]

31. Singhal V, Ackerman KE, Bose A, Torre Flores LP, Lee H, Misra M. Impact of route of estrogen administration on bone turnover markers in oligoamenorrheic athletes and its mediators. J Clin Endocrinol Metab. 2018;104(5):1449-58.

32. Bondy CA, Turner Syndrome Study Group. Care of girls and women with Turner syndrome: a guideline of the Turner Syndrome Study Group. J Clin Endocrinol Metab. 2007;92(1):10-25. [PubMed: 17047017]

33. Wiegratz I, Kutschera E, Lee JH, et al. Effect of four different oral contraceptives on various sex hormones and serum-binding globulins. Contraception. 2003;67(1):25-32. [PubMed: 12521654]

34. van der Vange N, Blankenstein MA, Kloosterboer HJ, Haspels AA, Thijssen JH. Effects of seven low-dose combined oral contraceptives on sex hormone binding globulin, corticosteroid binding globulin, total and free testosterone. Contraception. 1990;41(4):345-52. [PubMed: 2139843]

35. Boutroy S, Bouxsein ML, Munoz F, Delmas PD. In vivo assessment of trabecular bone microarchitecture by high-resolution peripheral quantitative computed tomography. J Clin Endocrinol Metab. 2005; 90(12):6508-15. [PubMed: 16189253] 
36. Riggs BL, Khosla S, Melton LJ III. Sex steroids and the construction and conservation of the adult skeleton. Endocr Rev. 2002;23(3):279-302. [PubMed: 12050121]

37. Manolagas SC, O'Brien CA, Almeida M. The role of estrogen and androgen receptors in bone health and disease. Nat Rev Endocrinol. 2013;9(12):699-712. [PubMed: 24042328]

38. Khosla S, Melton LJ III, Atkinson EJ, O'Fallon WM, Klee GG, Riggs BL. Relationship of serum sex steroid levels and bone turnover markers with bone mineral density in men and women: a key role for bioavailable estrogen. J Clin Endocrinol Metab. 1998;83(7):2266-74. [PubMed: 9661593]

39. Khosla S, Riggs BL, Robb RA, et al. Relationship of volumetric bone density and structural parameters at different skeletal sites to sex steroid levels in women. J Clin Endocrinol Metab. 2005;90(9):5096-103. [PubMed: 15998772]

40. Khosla S, Melton LJ 3rd, Achenbach SJ, Oberg AL, Riggs BL. Hormonal and biochemical determinants of trabecular microstructure at the ultradistal radius in women and men. J Clin Endocrinol Metab. 2006;91(3):885-91. [PubMed: 16368747]

41. Singhal V, Tulsiani SS, Campoverde KJ, et al. Impaired bone strength estimates at the distal tibia and its determinants in adolescents with anorexia nervosa. Bone. 2018;106:61-8. [PubMed: 28694162]

42. Farr JN, Khosla S, Miyabara Y, Miller VM, Kearns AE. Effects of estrogen with micronized progesterone on cortical and trabecular bone mass and microstructure in recently postmenopausal women. J Clin Endocrinol Metab. 2013;98(2):E249-57. [PubMed: 23322818]

43. Lespessailles E, Hambli R, Ferrari S. Osteoporosis drug effects on cortical and trabecular bone microstructure: a review of HR-pQCT analyses. Bonekey Rep. 2016;5:836. [PubMed: 27617082]

44. Southmayd EA, De Souza MJ. A summary of the influence of exogenous estrogen administration across the lifespan on the GH/IGF-1 axis and implications for bone health. Growth Horm IGF Res. 2017; 32:2-13. [PubMed: 27693042]

45. Jung-Hoffmann C, Kuhl H. Divergent effects of two low-dose oral contraceptives on sex hormonebinding globulin and free testosterone. Am J Obstet Gynecol. 1987;156(1):199-203. [PubMed: 2948387]

46. Sordal T, Grob P, Verhoeven C. Effects on bone mineral density of a monophasic combined oral contraceptive containing nomegestrol acetate/17beta-estradiol in comparison to levonorgestrel/ ethinyles-tradiol. Acta Obstet Gynecol Scand. 2012;91(11):1279-85. [PubMed: 22762147]

47. Cibula D, Skrenkova J, Hill M, Stepan JJ. Low-dose estrogen combined oral contraceptives may negatively influence physiological bone mineral density acquisition during adolescence. Eur $\mathbf{J}$ Endocrinol. 2012;166(6):1003-11. [PubMed: 22436400]

48. Scholes D, Ichikawa L, LaCroix AZ, et al. Oral contraceptive use and bone density in adolescent and young adult women. Contraception. 2010;81(1):35-40. [PubMed: 20004271]

49. Lattakova M, Borovsky M, Payer J, Killinger Z. Oral contraception usage in relation to bone mineral density and bone turnover in adolescent girls. Eur J Contracept Reprod Health Care. 2009;14(3): 207-14. [PubMed: 19565418]

50. Nappi C, Di Spiezio Sardo A, Acunzo G, et al. Effects of a low-dose and ultra-low-dose combined oral contraceptive use on bone turnover and bone mineral density in young fertile women: a prospective controlled randomized study. Contraception. 2003;67(5):355-9. [PubMed: 12742557]

51. Zhou S, Turgeman G, Harris SE, et al. Estrogens activate bone morphogenetic protein-2 gene transcription in mouse mesenchymal stem cells. Mol Endocrinol. 2003;17(1):56-66. [PubMed: 12511606]

52. Sato K, Nohtomi K, Shizume K, et al. 17 beta-estradiol increases calcium content in fetal mouse parietal bones cultured in serum-free medium only at physiological concentrations. Bone. 1996;19(3): 213-21. [PubMed: 8873961]

53. Gorrill MJ, Marshall JR. Pharmacology of estrogens and estrogen-induced effects on nonreproductive organs and systems. J Reprod Med. 1986;31(9 Suppl):842-7. [PubMed: 3772905]

54. Caputo CB, Meadows D, Raisz LG. Failure of estrogens and androgens to inhibit bone resorption in tissue culture. Endocrinology. 1976;98 (4):1065-8. [PubMed: 945150]

55. Liskova M Influence of estrogens on bone resorption in organ culture. Calcif Tissue Res. 1976;22(2):207-18. [PubMed: 1000354] 
56. Scholes D, Hubbard RA, Ichikawa LE, et al. Oral contraceptive use and bone density change in adolescent and young adult women: a prospective study of age, hormone dose, and discontinuation. J Clin Endocrinol Metab. 2011;96(9):E1380-7. [PubMed: 21752879]

57. Harel Z, Riggs S, Vaz R, Flanagan P, Harel D, Machan JT. Bone accretion in adolescents using the combined estrogen and progestin transdermal contraceptive method Ortho Evra: a pilot study. J Pediatr Adolesc Gynecol. 2010;23(1):23-31. [PubMed: 19647454]

58. Seifert-Klauss V, Prior JC. Progesterone and bone: actions promoting bone health in women. J Osteoporos. 2010;2010:845180. [PubMed: 21052538]

59. Prior JC, Vigna YM, Barr SI, Rexworthy C, Lentle BC. Cyclic medroxyprogesterone treatment increases bone density: a controlled trial in active women with menstrual cycle disturbances. Am J Med. 1994; 96(6):521-30. [PubMed: 8017450]

60. Hergenroeder AC, Smith EO, Shypailo R, Jones LA, Klish WJ, Ellis K. Bone mineral changes in young women with hypothalamic amenorrhea treated with oral contraceptives, medroxyprogesterone, or placebo over 12 months. Am J Obstet Gynecol. 1997;176(5):1017-25. [PubMed: 9166162]

61. Cromer BA, Stager M, Bonny A, et al. Depot medroxyprogesterone acetate, oral contraceptives and bone mineral density in a cohort of adolescent girls. J Adolesc Health. 2004;35(6):434-41. [PubMed: 15581522]

62. Scholes D, LaCroix AZ, Ichikawa LE, Barlow WE, Ott SM. Change in bone mineral density among adolescent women using and discontinuing depot medroxyprogesterone acetate contraception. Arch Pediatr Adolesc Med. 2005;159(2):139-44. [PubMed: 15699307]

63. Berenson AB, Breitkopf CR, Grady JJ, Rickert VI, Thomas A. Effects of hormonal contraception on bone mineral density after 24 months of use. Obstet Gynecol. 2004;103(5 Pt 1):899-906. [PubMed: 15121563]

64. Clark MK, Sowers MR, Nichols S, Levy B. Bone mineral density changes over two years in firsttime users of depot medroxyprogesterone acetate. Fertil Steril. 2004;82(6):1580-6. [PubMed: 15589863]

65. Scholes D, LaCroix AZ, Ichikawa LE, Barlow WE, Ott SM. Injectable hormone contraception and bone density: results from a prospective study. Epidemiology. 2002;13(5):581-7. [PubMed: 12192229]

66. Lara-Torre E, Edwards CP, Perlman S, Hertweck SP. Bone mineral density in adolescent females using depot medroxyprogesterone acetate. J Pediatr Adolesc Gynecol. 2004;17(1):17-21. [PubMed: 15010034]

67. Walsh JS, Eastell R, Peel NF. Effects of depot medroxyprogesterone acetate on bone density and bone metabolism before and after peak bone mass: a case-control study. J Clin Endocrinol Metab. 2008;93(4): 1317-23. [PubMed: 18230659]

68. Kuhl H Comparative pharmacology of newer progestogens. Drugs. 1996;51(2):188-215. [PubMed: 8808163]

69. Kuhl H Pharmacology of estrogens and progestogens: Influence of different routes of administration. Climacteric. 2005;8(Suppl 1):3-63.

70. Sudi K, Ottl K, Payerl D, Baumgartl P, Tauschmann K, Muller W. Anorexia athletica. Nutrition. 2004;20(7-8):657-61. [PubMed: 15212748]

71. Martinsen M, Bratland-Sanda S, Eriksson AK, Sundgot-Borgen J. Dieting to win or to be thin? A study of dieting and disordered eating among adolescent elite athletes and non-athlete controls. $\mathrm{Br}$ J Sports Med. 2010;44(1):70-6. [PubMed: 20026698]

72. Berger C, Goltzman D, Langsetmo L, et al. Peak bone mass from longitudinal data: Implications for the prevalence, pathophysiology, and diagnosis of osteoporosis. J Bone Miner Res. 2010;25(9):1948-57. [PubMed: 20499378]

73. Samelson EJ, Broe KE, Xu H, et al. Cortical and trabecular bone microarchitecture as an independent predictor of incident fracture risk in older women and men in the bone microarchitecture international consortium (BoMIC): a prospective study. Lancet Diabetes Endocrinol. 2019;7(1):34-43. [PubMed: 30503163]

74. [No authors listed]. ACOG Practice Bulletin No. 141: Management of menopausal symptoms. Obstet Gynecol. 2014;123(1):202-16. [PubMed: 24463691] 
75. American Academy of Pediatrics Committee on Adolescence, Blythe MJ, Diaz A. Contraception and adolescents. Pediatrics. 2007; 120(5):1135-48. [PubMed: 17974753] 


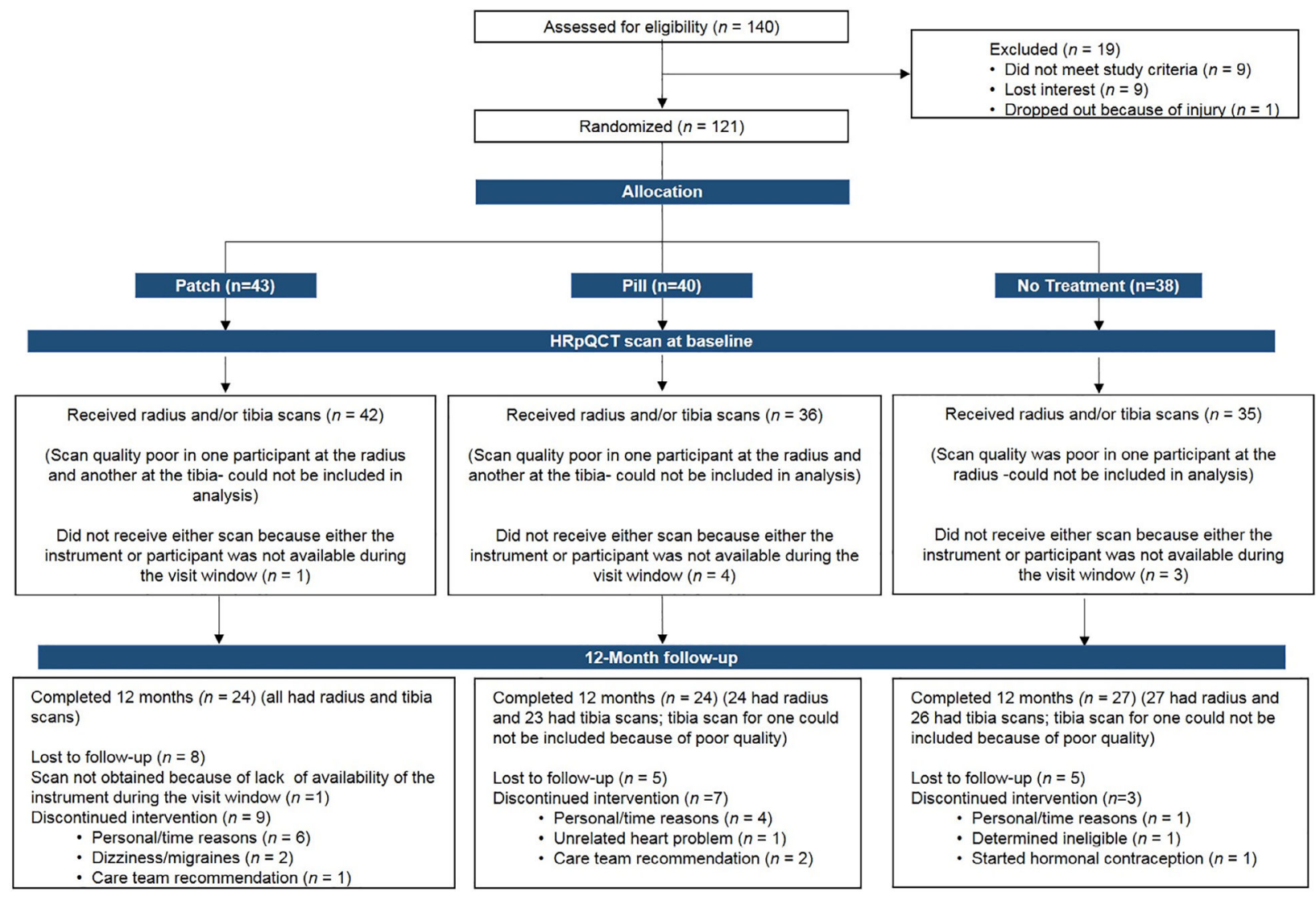

Fig. 1.

Flowchart of oligoamenorrheic athletes recruited for this study and attrition according to randomization group. 

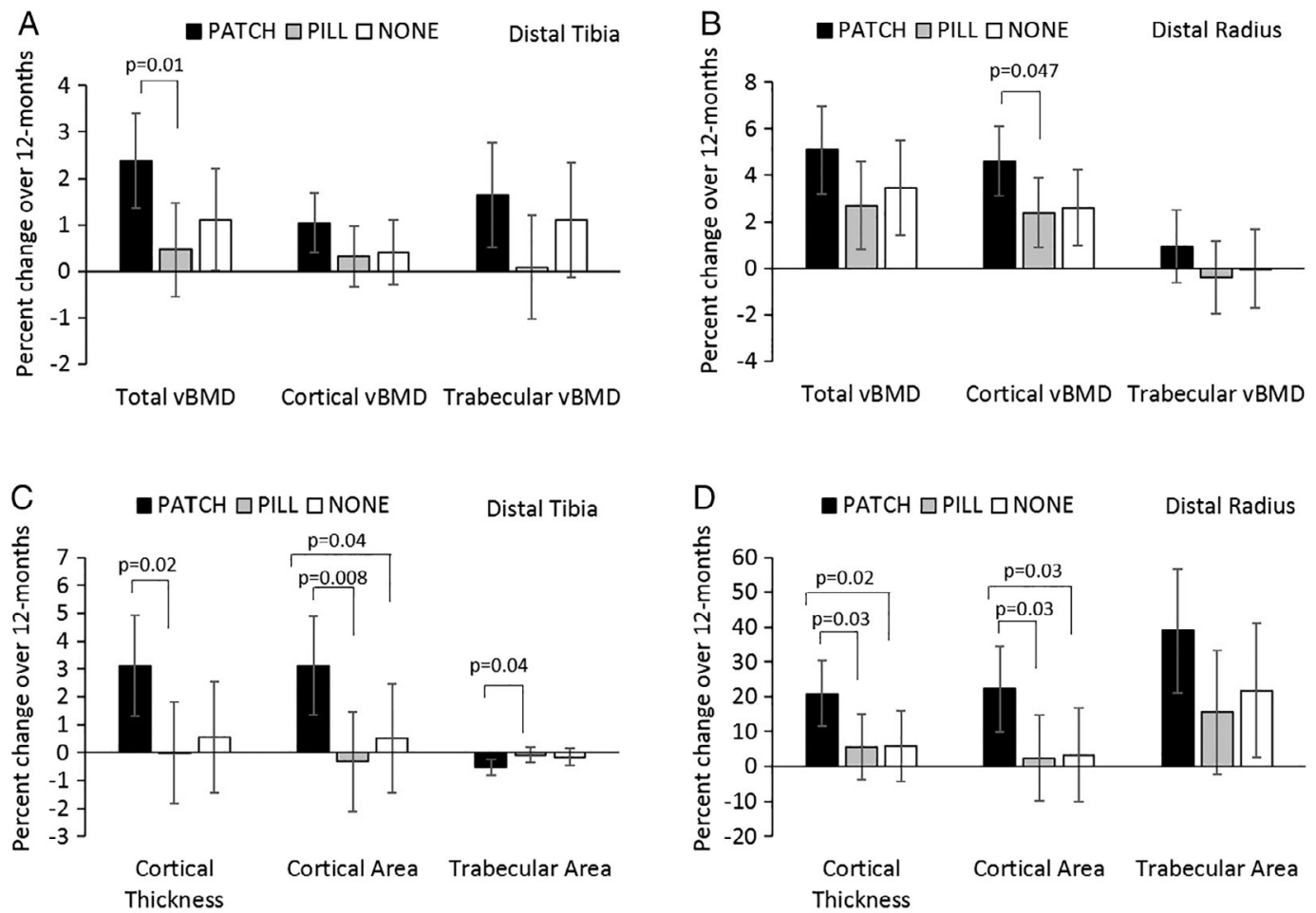

Fig. 2.

Percent change in compartmental volumetric BMD and bone geometry parameters at the distal tibia (A and $\mathrm{C}$ ) and distal radius (B and D) in oligoamenorrheic athletes randomized to the PATCH, PILL, or no-estrogen (NONE). 

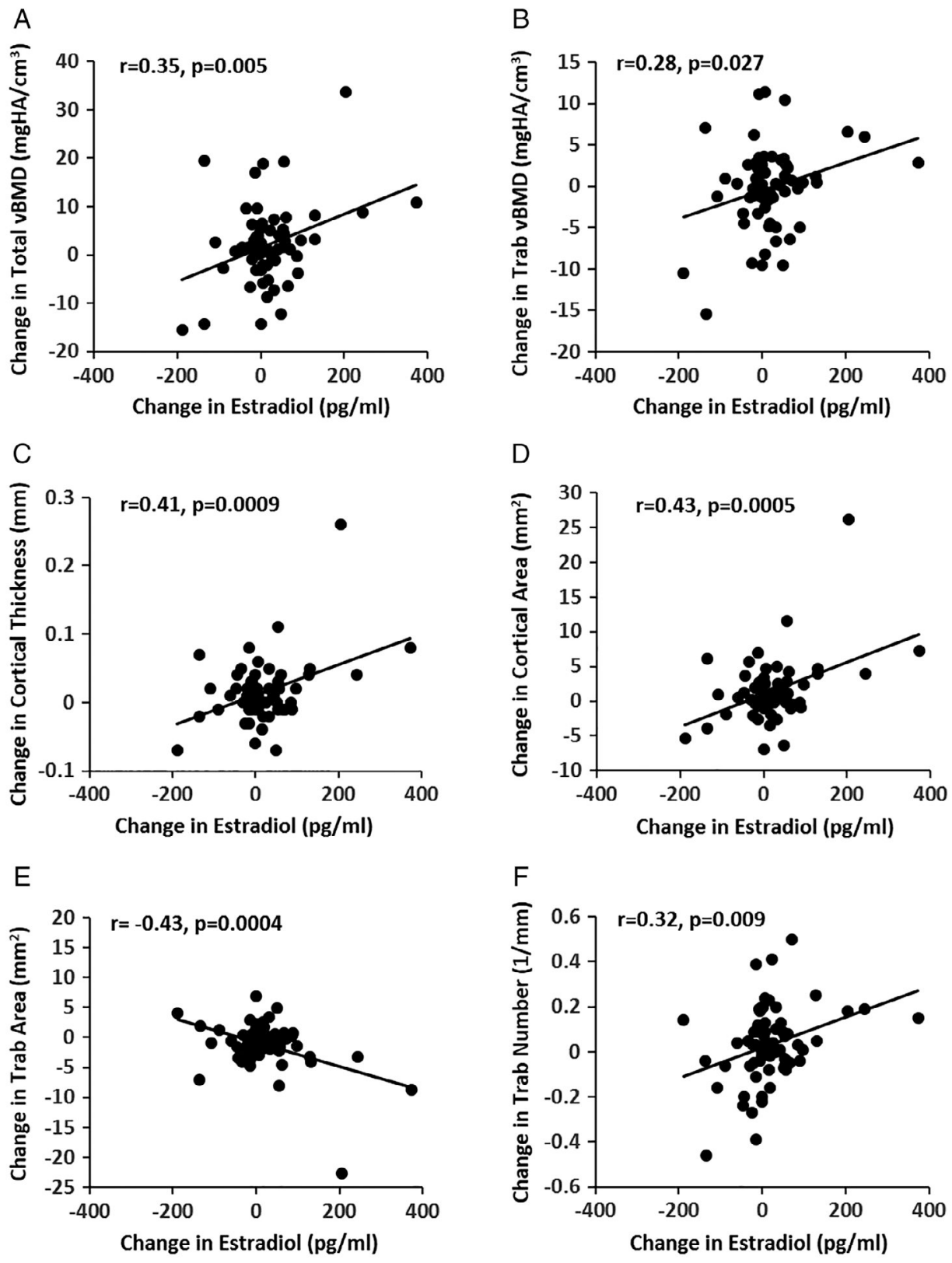

Fig. 3.

Associations of changes in estradiol with changes in volumetric BMD (A and B), bone geometry (C, D, and E), and microarchitectural parameters $(\mathrm{F})$ at the distal tibia. 


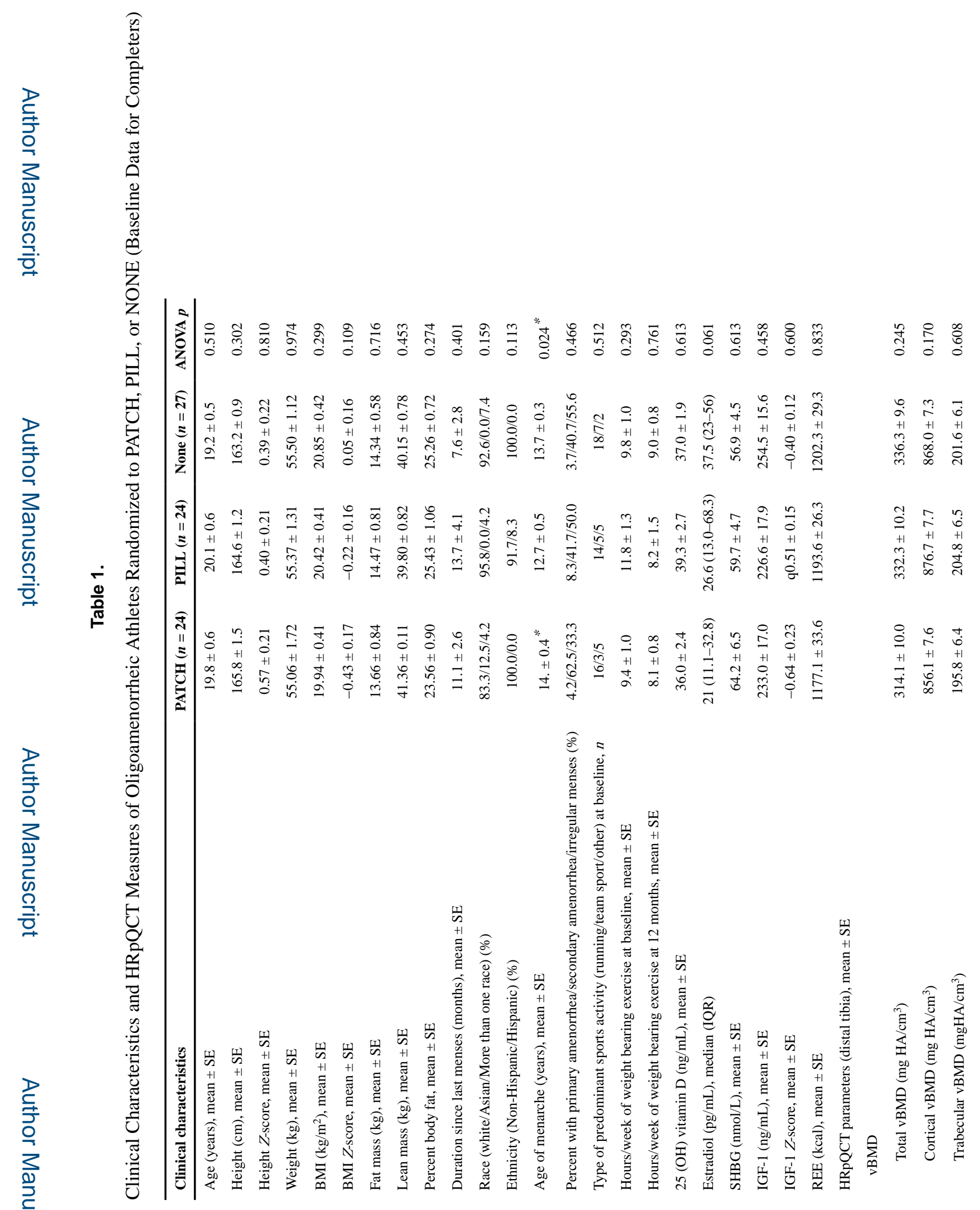

J Bone Miner Res. Author manuscript; available in PMC 2021 February 01. 
Ackerman et al.

Page 22

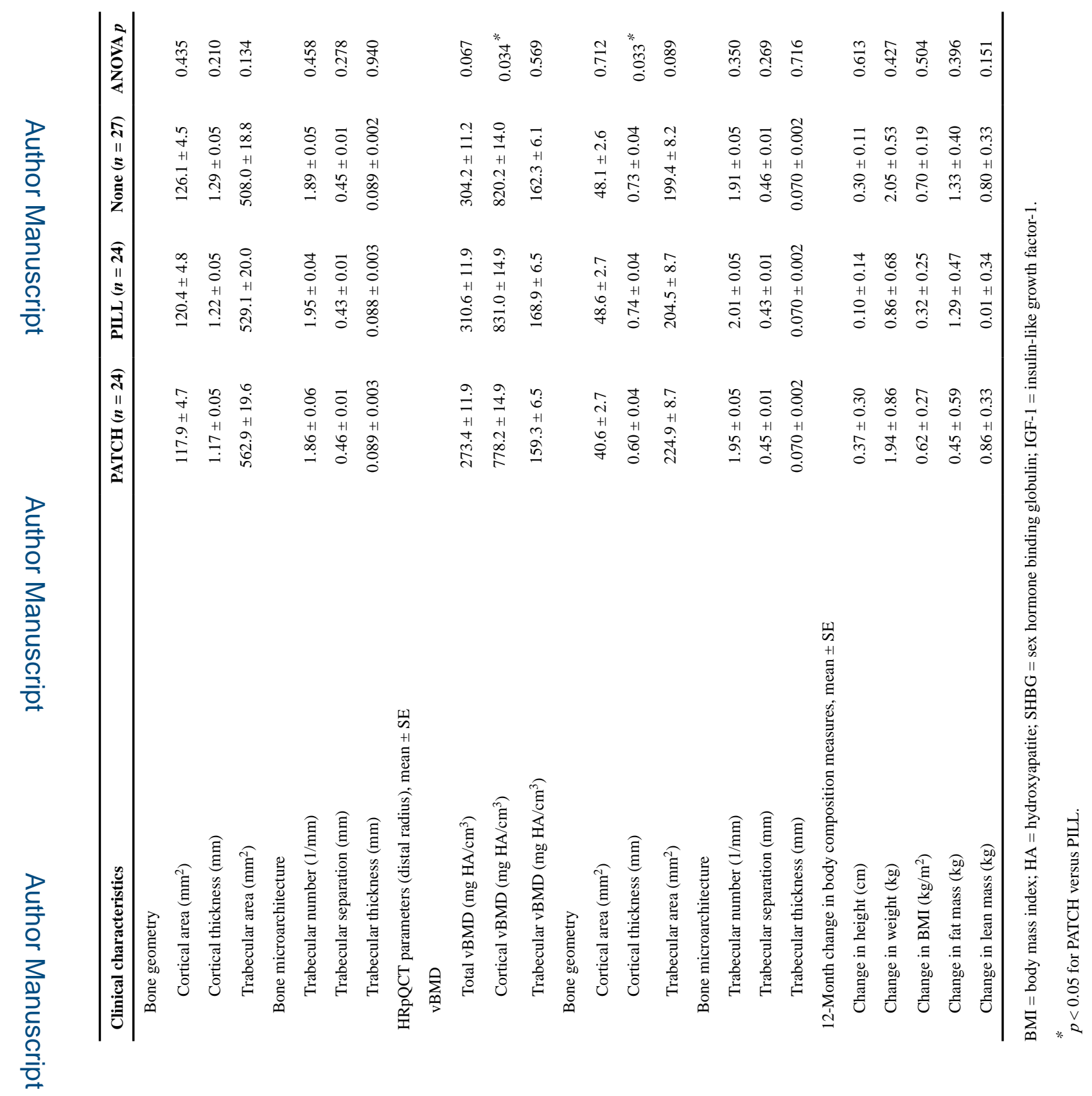

로을

J Bone Miner Res. Author manuscript; available in PMC 2021 February 01. 


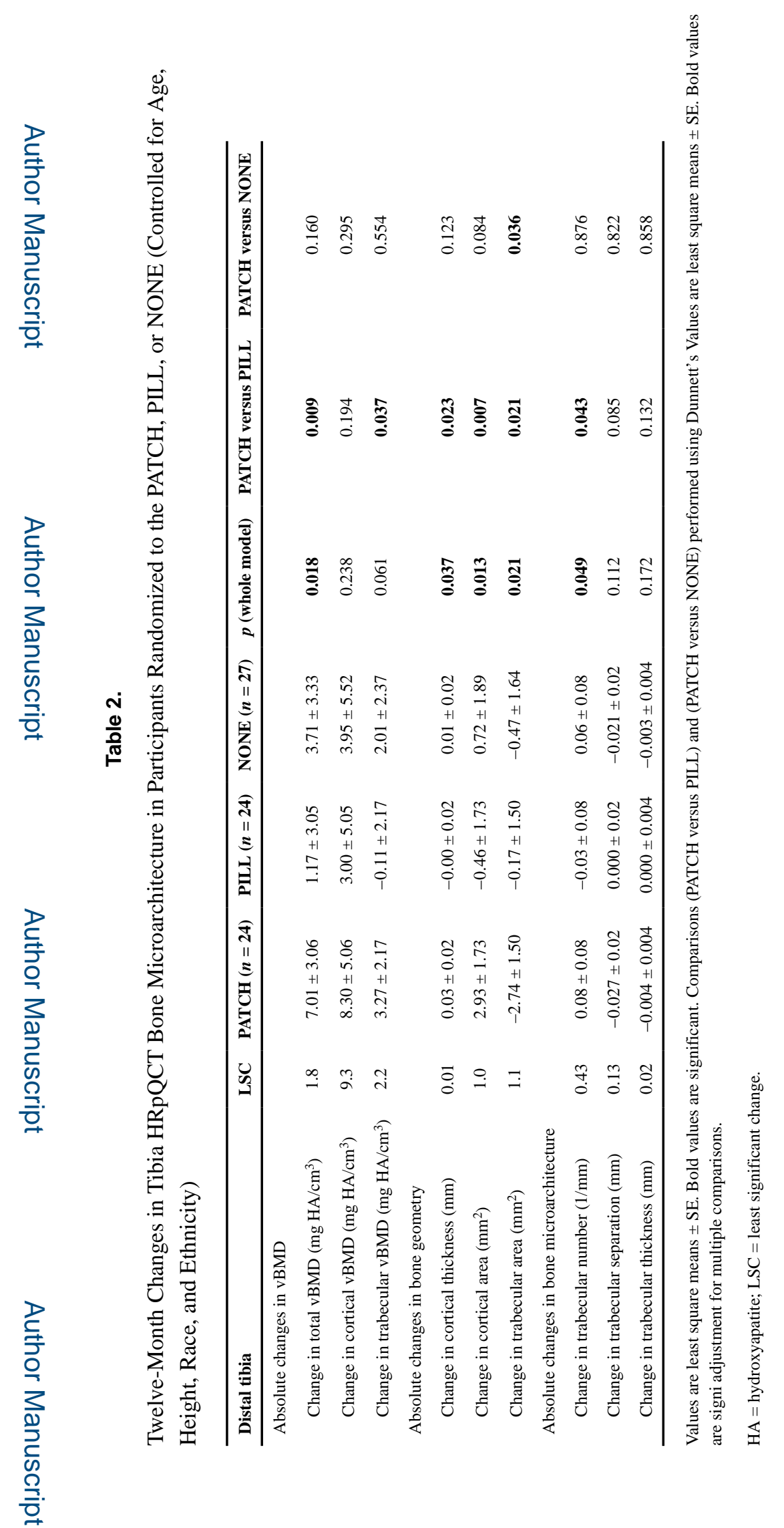

J Bone Miner Res. Author manuscript; available in PMC 2021 February 01. 


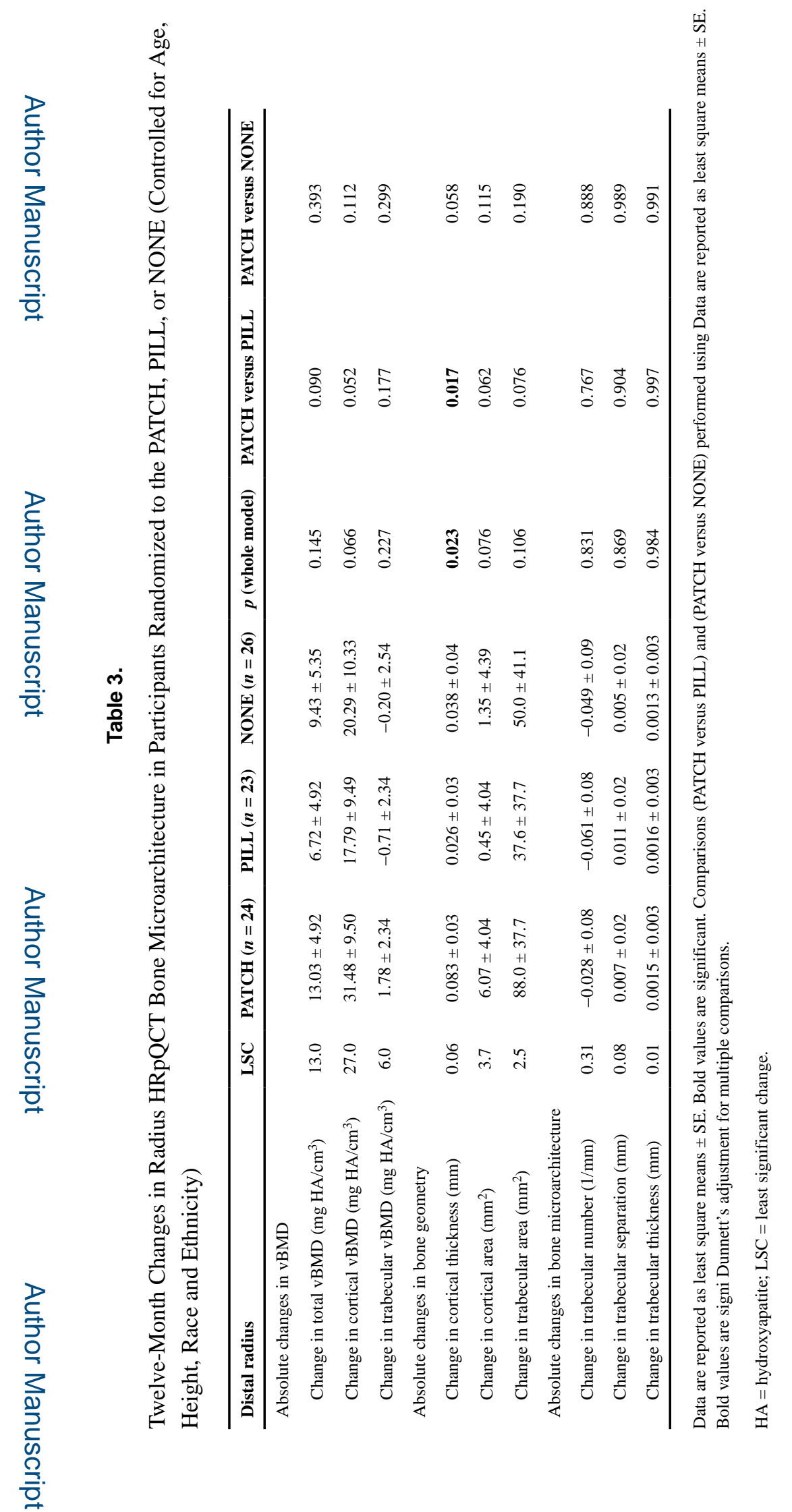

J Bone Miner Res. Author manuscript; available in PMC 2021 February 01. 


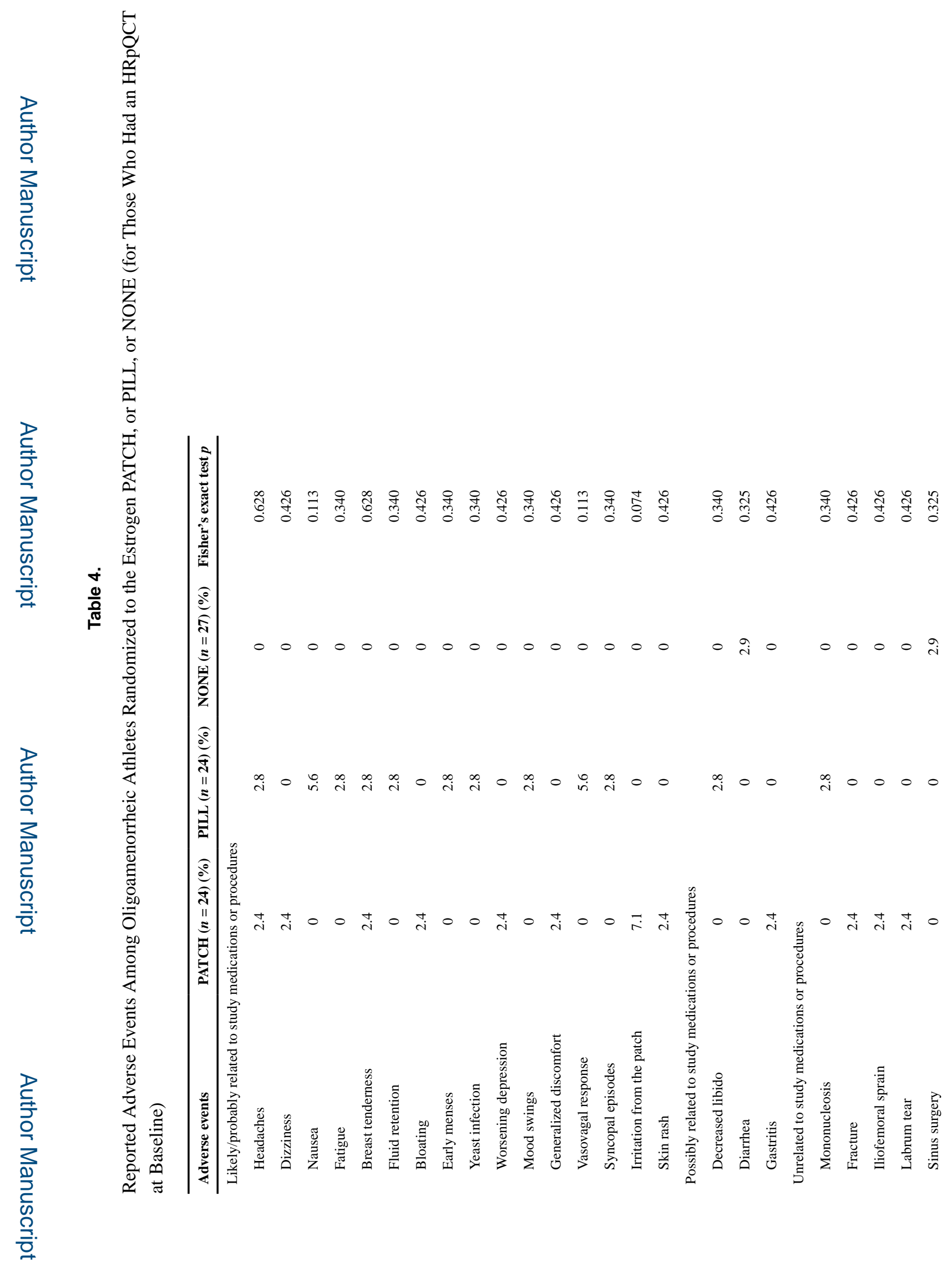

J Bone Miner Res. Author manuscript; available in PMC 2021 February 01. 


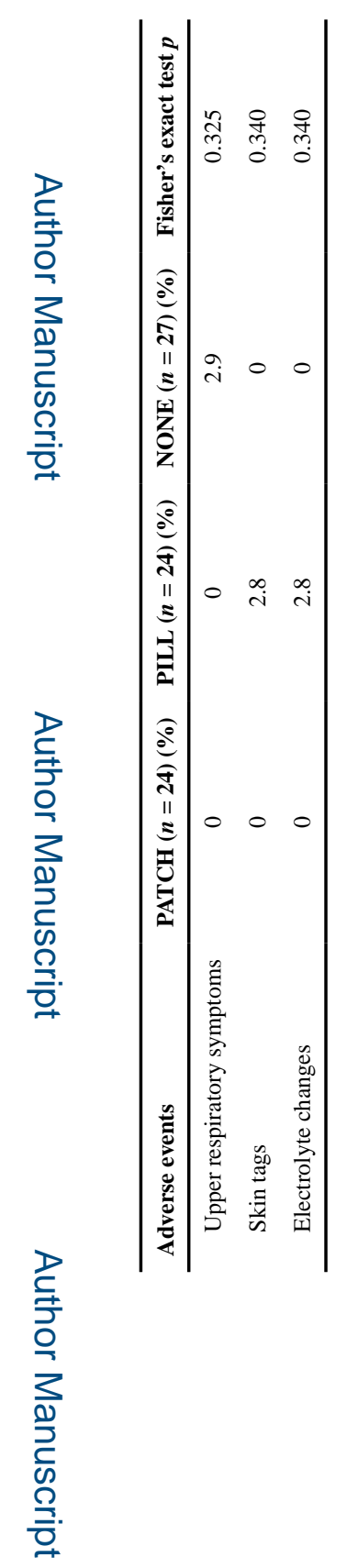

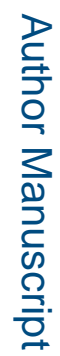

